\title{
Molecular Docking, Design and Pharmacokinetics Study of Some Anti-Epilepsy Compounds
}

\author{
Gideon Adamu Shallangwa ${ }^{1}$, Adamu Uzairu ${ }^{1} \&$ Usman Abdulfatai $^{1}$ \\ ${ }^{1}$ Department of Chemistry, Ahmadu Bello University P.M.B. 1044, Zaria-Nigeria \\ Correspondence: Usman Abdulfatai, Department of Chemistry, Ahmadu Bello University P.M.B. 1044, \\ Zaria-Nigeria.
}

Received: July 4, 2021

Accepted: August 11, 2021

Online Published: September 26, 2021

doi:10.5539/mas.v15n5p67

URL: https://doi.org/10.5539/mas.v15n5p67

\begin{abstract}
To complement experimental study, in-silico molecular docking was carried out to access and understand the interacting binding energy dynamism of some experimental potent anti-epilepsy compounds on the $\mathrm{GABA}_{\mathrm{T}}$ enzyme's (A causative agent for epilepsy disorder) binding site. The Autoduck vina docking option of Pyrx multipurpose simulation software was used in this study to perform docking simulations. Four anti-epilepsy drug (AED) candidates was designed (Anti-epilepsy disorders) through a structural based drug technique. All the designed AED candidates shows stable binding interaction energies. Out of the four designed compounds, 9-decyl-8-methyl-6-(1H-1, 2, 4-triazol-1-yl)-9H-purine shows better binding energy with GABA ${ }_{\mathrm{T}}$. The docked energy score of the compound $(7.8 \mathrm{Kcal} / \mathrm{mole})$ was better than the binding energy scores of the standard anti-epilepsy compounds, Carbamazepine $(-6.5 \mathrm{kcal} / \mathrm{mole})$ and Valproate $(-4.5 \mathrm{kcal} / \mathrm{mole})$. With this level of interaction, this drug candidate could bind better on the enzyme's binding site. Also, the pharmacokinetic properties investigation revealed that all designed AED candidates could be synthesized easily, absorbed, distributed, metabolized and excreted from the body. Therefore, this drug candidate could be synthesized and used effectively for the treatment and management of epilepsy disorder.
\end{abstract}

Keywords: AEDs, ADMET, DFT, Spartan 14 software, GABA

\section{Introduction}

Over thirty-nine (39) neurological disorders that arise as a result of human seizures are broadly called epilepsy (McCormick and Contreras, 2001). Depending on the global population at any time, this neurological disorder was reported to afflict over $0.99-1.7 \%$ of our population (McNamara, 2001). This account for approximately 500 million of the present 7.8 billion of the world population (Abdulfatai et al., 2016). Presently, 25-35\% of the anticonvulsant drugs in use has not been completely effective in stabilized this disorder (Wang et al., 2014; Meador and Newer, 2003).

For the last decade, tremendous improvement in the designing of many anticonvulsant drugs has been witnessed from aryl semicarbazones, valproic acid, Phenobarbital, benzodiazepines and phenytoin to vigabatrin (Abdulfatai et al., 2016). Research shows that the Gamma-aminobutyric acid transferase $\left(\mathrm{GABA}_{\mathrm{T}}\right)$ has been a standard receptor for most of the AEDs. Inhibiting the activities of this receptor has been reported to be effective in reducing the human seizure disorder (Stangler et al., 2002; Storici et al., 1999). The plan to design alternative AEDs without prolong side effects has been the desire of many pharmaceutical researchers (Abdulfatai et al., 2017; Meador and Newer, 2003).

In recent times, many pharmaceutical companies have developed an interest in the usage of the in-silco method of drug development (Abdulfatai et al., 2017; Meador and Newer, 2003; Abdulfatai et al., 2020). This method is simple, fast and reliable and has shown to be very important in designing better drug candidates for different ailments. In this case, the in-silico method of drug design can be used to screen large structures of potent AEDs compounds. These potent structures can be modified to obtain better potent compounds against convulsion (Langer and Hoffmann, 2001; Kitchen et al., 2004). To complement the experimental work of Wang and his co-researchers (Wang et al., 2014), the molecular docking simulation technique was used to design more potent AEDs that will be able to inhibit the $\mathrm{GABA}_{\mathrm{T}}$ receptor (A causative agent for epilepsy). 


\section{Materials and Methods}

\subsection{Receptors and Ligands Collections}

Some set of reliable experimental anti-epilepsy data sets along with their properties, which were made up of nine (09) potent compounds were collected from the work of Wang and his co-researchers (Wang et al., 2014). These selected experimental AEDs were shown to possessed better activities than co-compounds in the literature. The reliable data sets were drawn with the aid of chemdraw software into 2D structural forms (Table 1) and saved in cdx format. To make the atoms of the compounds energetically stable (to look real), the drawn structures were geometrically optimized with the aid of DFT (Density functional theory) algorithm of Spartan 14 software. Moreover, the $\mathrm{GABA}_{T}$ in figure 1 was successfully retrieved from the protein data bank (http://www.rcsb.org/pdb).

Table 1. Two dimensional structures of some anticonvulsant and their anti-convulsion activities

\begin{tabular}{|c|c|c|}
\hline $\mathrm{S} / \mathrm{N}$ & 2D structures & Anti-convulsion activities $\left(\mathrm{ED}_{50}\right)$ \\
\hline 1 & & 51.2 \\
\hline 2 & & 51.9 \\
\hline 3 & & 43.9 \\
\hline 4 & & 31.5 \\
\hline 5 & & 33.2 \\
\hline 6 & & 23.4 \\
\hline
\end{tabular}


7

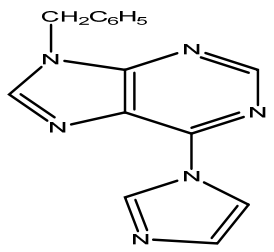
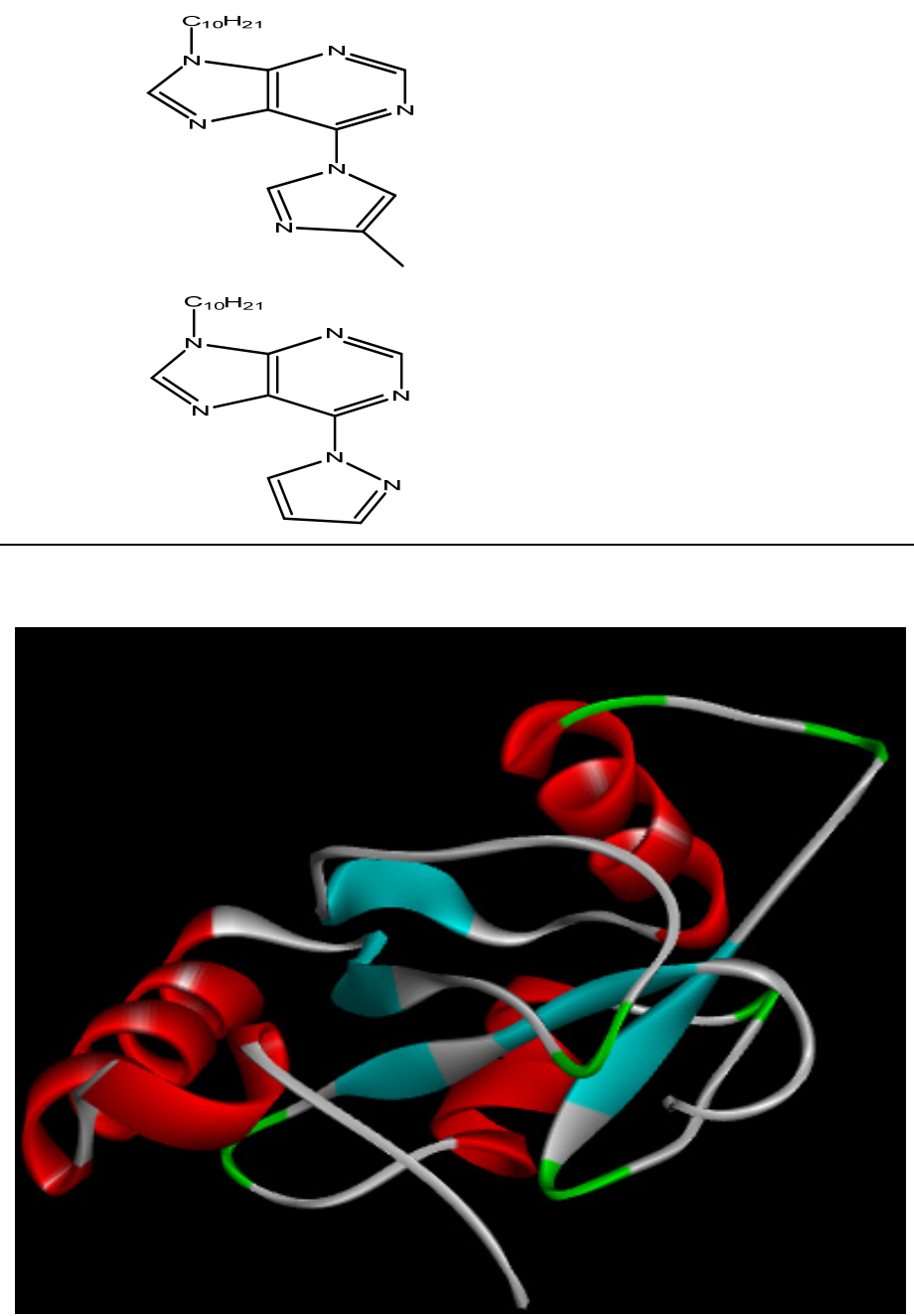

Figure 1. Gamma-aminobutyric acid transferase $\left(\mathrm{GABA}_{\mathrm{T}}\right)$ receptor

\subsection{Molecular Docking Simulation Learning Methodology}

The Autoduck vina docking option of Pyrx multipurpose simulation software was used in this study to perform docking simulations. Both the receptor and the ligands were adequately prepared, saved in pdf format with help of discovery studio software, uploaded into the pyrx software and converted to pdqt format. $\mathrm{GABA}_{\mathrm{T}}$ receptor (Figure 1) and the ligands (Table 1) were transferred unto the $\mathrm{X}, \mathrm{Y}$ and $\mathrm{Z}$ grid of the pyrx software interface after which autoduck vina option of the software was invoked. After several minutes of selective ligand poses on the binding site of the $\mathrm{GABA}_{\mathrm{T}}$ enzyme, the docked pose with the best orientation binding energy was selected, analyzed and recorded (Kitchen et al., 2004).

\section{Results and Analysis}

\subsection{Assessment of Molecular Docking Binding Energy}

The investigation of the molecular docking study was carried out to access and understand the interacting binding energy dynamism of some obtained experimental (Table 1) potent anti-epilepsy compounds on the $\mathrm{GABA}_{\mathrm{T}}$ enzyme (Figure 1). In table 2, all the selected (most potent AEDs) anti-epilepsy drug candidates were found to have docking scores ranges of -5.1 to $-6.8 \mathrm{kcal} / \mathrm{mol}$. The 9-decyl-6-(1H-1,2,4-triazol-1-yl)-9H-purine $(\mathrm{S} / \mathrm{N}=6)$ with the dynamic docking score of $-6.8 \mathrm{kcal} / \mathrm{mole}$ was found to be the only AEDs with the 
highest/better binding energy among the co-compounds (Table 2). Therefore, 9-decyl-6-(1H-1, 2, 4-triazol-1-yl)-9H-purine could function well by inhibiting the activities of $\mathrm{GABA}_{\mathrm{T}}$ on the binding site. This is because the magnitude of the docking scores is directly proportional to the capacity to initiate ligand-protein actions.

Table 2. Two-dimensional structures of anti-epilepsy compounds and their binding energies

\begin{tabular}{|c|c|c|}
\hline $\mathrm{S} / \mathrm{N}$ & 2D structures & $\begin{array}{c}\text { Binding } \\
\text { Affinity } \\
\text { Kcal/mole }\end{array}$ \\
\hline
\end{tabular}

1<smiles>Cn1cnc2c1ncn1cnnc21</smiles><smiles>c1ccc(CCn2cnc3c2ncn2cnnc32)cc1</smiles><smiles>CCCn1cnc2c(-n3cncn3)ncnc21</smiles><smiles></smiles>

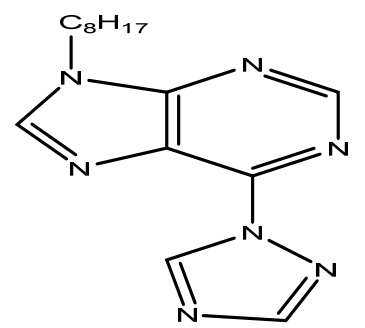<smiles></smiles> 
7<smiles></smiles>

8<smiles>Cc1cn2c3ncnc4ncnc-4c3ncn12</smiles>

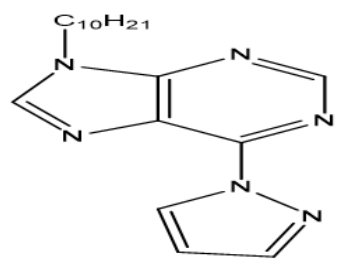

\subsection{Novel Anti-Epilepsy Compounds Designs and Analysis}

Computational drug design is the process of using software and computer to virtual design new drug that ought to be designed physical with the help of laboratory reagents and test tubes. In this case, to design reliable AEDs, structure-based drug design was used to carry out new structural modifications by; (i) investigating the docking binding energies on the experimental compounds, (ii) identifying the compound with the best docking score, and (iii) performing structural modification on the selected ligand/compound.

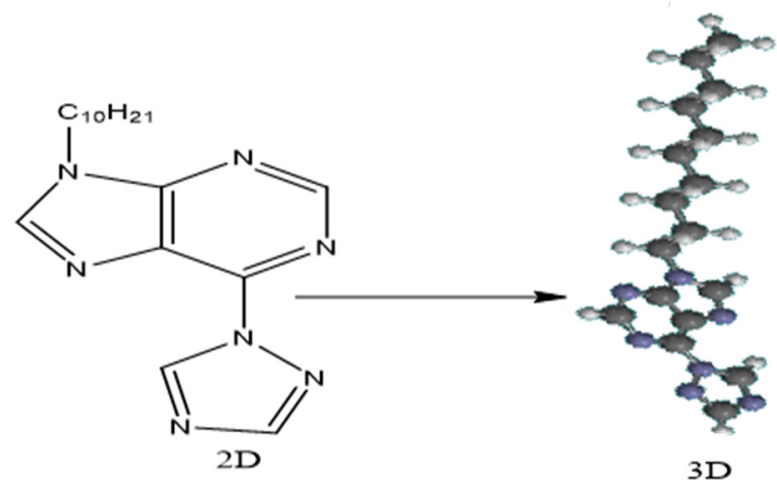

Figure 2. 2D and 3D structure of the template drug candidate

The 9-decyl-6-(1H-1, 2, 4-triazol-1-yl)-9H-purine ( $\mathrm{S} / \mathrm{N}=6)$ with the dynamic docking score of $-6.8 \mathrm{kcal} / \mathrm{mole}$ was found to be the only AED candidate with the highest/better binding energy among the potent co-compounds (Table 2). Therefore, it was chosen as the drug candidate template to which further structural modification was made (Figure 2). The addition of $\mathrm{CH}_{3}$ and $\mathrm{N}$ across the template structure in figure 2 shows some dramatic improvement in binding energy scores (Table 3). To calculate the binding energy of the new compounds, all the new structures were converted to 3D, geometrically optimized with DFT B3LYP/6-31G of Spartan 14 software and saved in the pdb format. Thereafter, the 3D improved structures were exported into the pyrx software, converted to pdbqt and subsequently docked into the binding site of $\mathrm{GABA}_{\mathrm{T}}$ receptor model. The docked energy scores of all the newly designed AEDs (Table 3) were analyzed to be better than the experimental calculated energy scores in table 2 . The average docking energies range of the newly designed epilepsy inhibitors was calculated to be -6.9 to $-7.8 \mathrm{kcal} / \mathrm{mole}$. The 9-decyl-8-methyl-6-(1H-1, 2, 4-triazol-1-yl)-9H-purine was found to be the AED with the highest docking score of $7.8 \mathrm{kcal} / \mathrm{mole}$. The docking score of this drug candidate was also found to be better/higher than the commercially sold anti-epilepsy drug (Table 3). 
Table 3. 2D structures, names of the designed anti-epilepsy compounds and their binding energies

$\mathrm{S} / \mathrm{N}$

3-decyl-7-(1H-tetrazol-1-yl)-3H-[1, 2, 3] triazolo [4, 5d] pyrimidine

2<smiles>CCn1cnc2c(-n3cncn3)nc(C)nc21</smiles>

9-decyl-2-methyl-6-(1H-1, 2, 4-triazol-1-yl)-9H-purine

3<smiles>CCn1cnc2c(-n3cnnn3)nc(C)nc21</smiles>

9-decyl-2-methyl-6-(1H-tetrazol-1-yl)-9H-purine

4<smiles>Cc1nc2c(-n3cncn3)ncnc2n1C</smiles>

9-decyl-8-methyl-6-(1H-1, 2, 4-triazol-1-yl)-9H-purine

Stan-dard<smiles>NC(=O)N1c2ccccc2C=Cc2ccccc21</smiles>

Carbamazepine

Stan-dard<smiles>CCCC(CCC)C(=O)[O-]</smiles>

Valproate

In Figure 3, Arginine (ARG 69), Isoleucine (ILE 23), Leucine - (LEU 57 and 65), Lysine - (LYS 50), Glutamine (GLU 19), Valine (VAL 53), Tyrosine (TYR 51), Glutamine (GLU 19) and Proline (PRO 54) amino acids were found to forms van der waal, conventional hydrogen and carbon-hydrogen bonds with the structure of 9-decyl-8-methyl-6-(1H-1, 2, 4-triazol-1-yl)-9H-purine. This anti-epilepsy drug candidate was also analyzed to 
form a hydrogen bond length of $2.96 \mathrm{~A}^{\circ}$ with Leucine (LEU 52) amino acid through the second nitrogen atom. The bonds of the 9-decyl-8-methyl-6-(1H-1, 2, 4-triazol-1-yl)-9H-purine formed with the various amino acids were responsible for the excellent binding energy score of $7.8 \mathrm{kcal} / \mathrm{mole}$. This energy score was found to be better than the other energy scores of other co-designed drug candidates in table 3. Therefore, the interactions of 9-decyl-8-methyl-6-(1H-1, 2, 4-triazol-1-yl)-9H-purine was found to be strong enough to inhibit/reduces the activities of $\mathrm{GABA}_{\mathrm{T}}$, since the hyperactive $\mathrm{GABA}_{\mathrm{T}}$ has been reported to be responsible for convulsion (Stangler et al., 2002; Storici et al., 1999). All the docking energy scores of the four designed anti-epilepsy compounds (Table 3) were better than the binding energy scores of the standard anti-epilepsy compounds, Carbamazepine $(-6.5 \mathrm{kcal} / \mathrm{mole})$ and Valproate $(-4.5 \mathrm{kcal} / \mathrm{mole})$.

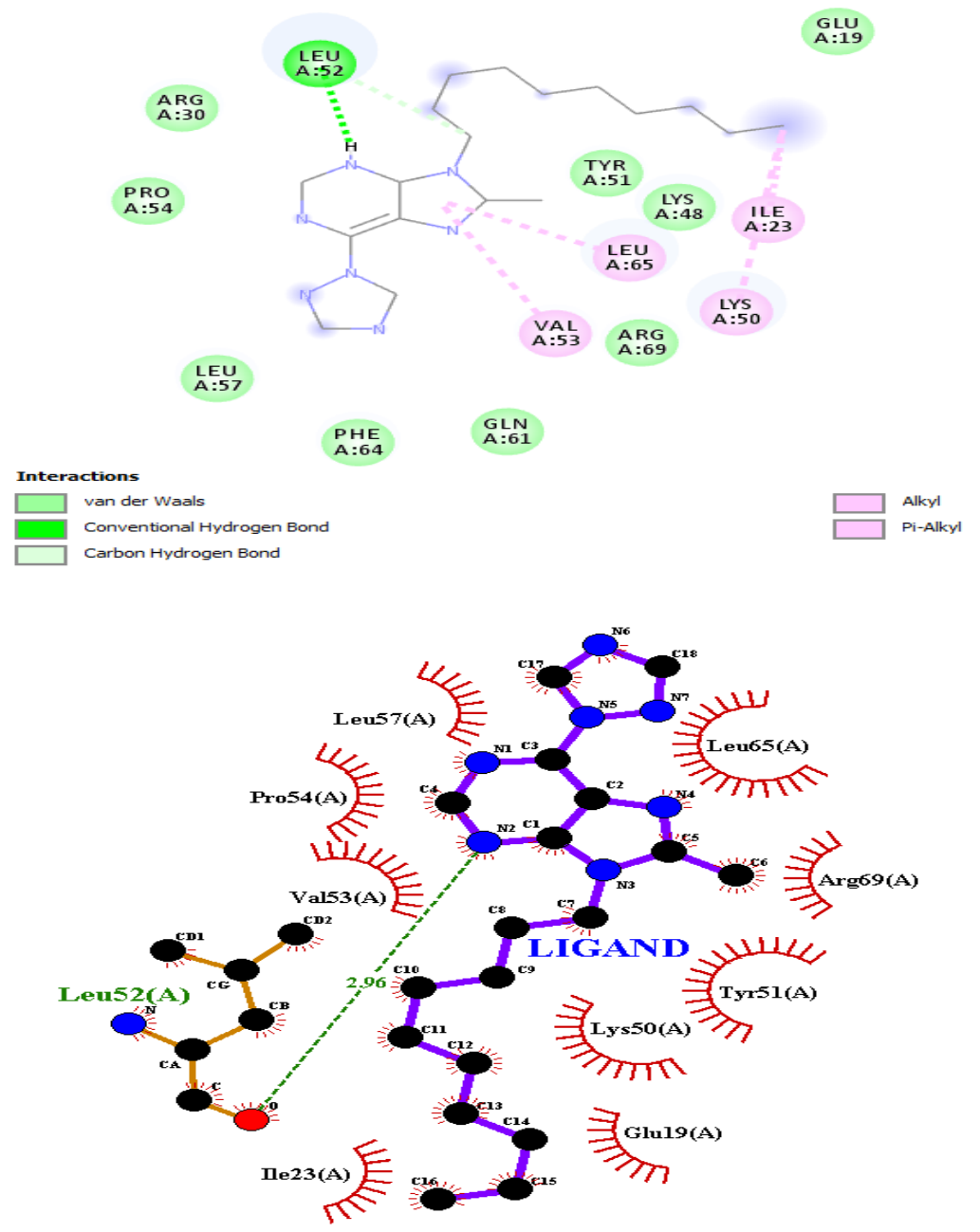

Figure 3. 2D ligand structures (A and B) binding site amino acids of $\mathrm{GABA}_{\mathrm{T}}$ receptor

\subsection{The ADMET Study of the Best Docked Anticonvulsant Compound}

For any designed drug to get to the target site in the living body, the rules of five properties, ADMET (absorption, metabolism, distribution, toxicity and elimination) which guide the smooth movement of drug candidate must be examined (Xu et al., 2012). Figure 4 show the best structurally designed AED compound (9-decyl-8-methyl-6-(1H-1, 2, 4-triazol-1-yl)-9H-purine) and its ADMET rules of five properties. The outcomes of pharmacokinetic analysis show that the 9-decyl-8-methyl-6-(1H-1, 2, 4-triazol-1-yl)-9H-purine with the best binding energy of $7.8 \mathrm{kcal} / \mathrm{mole}$ has high gastrointestinal absorption capability and high blood-brain barrier (BBB) permissibility (Figure 4). This drug candidate has favorable solubility and permeability properties since it shows moderate water solubility and better lipophilicity (Consensus $\log P_{\mathrm{o} / \mathrm{w}}$ ) properties (Figure 4). Also, the pharmacokinetics in-silico results in figure 4 revealed that this drug candidate (9-decyl-8-methyl-6-(1H-1, 2, 4-triazol-1-yl)-9H-purine) has a very easy synthetic accessibility (Very easy to synthesize) and can be consumed by the body (bioavailability) (Lipinski, 2016; Martin, 2005; Ertl and Schuffenhauer, 2009). 


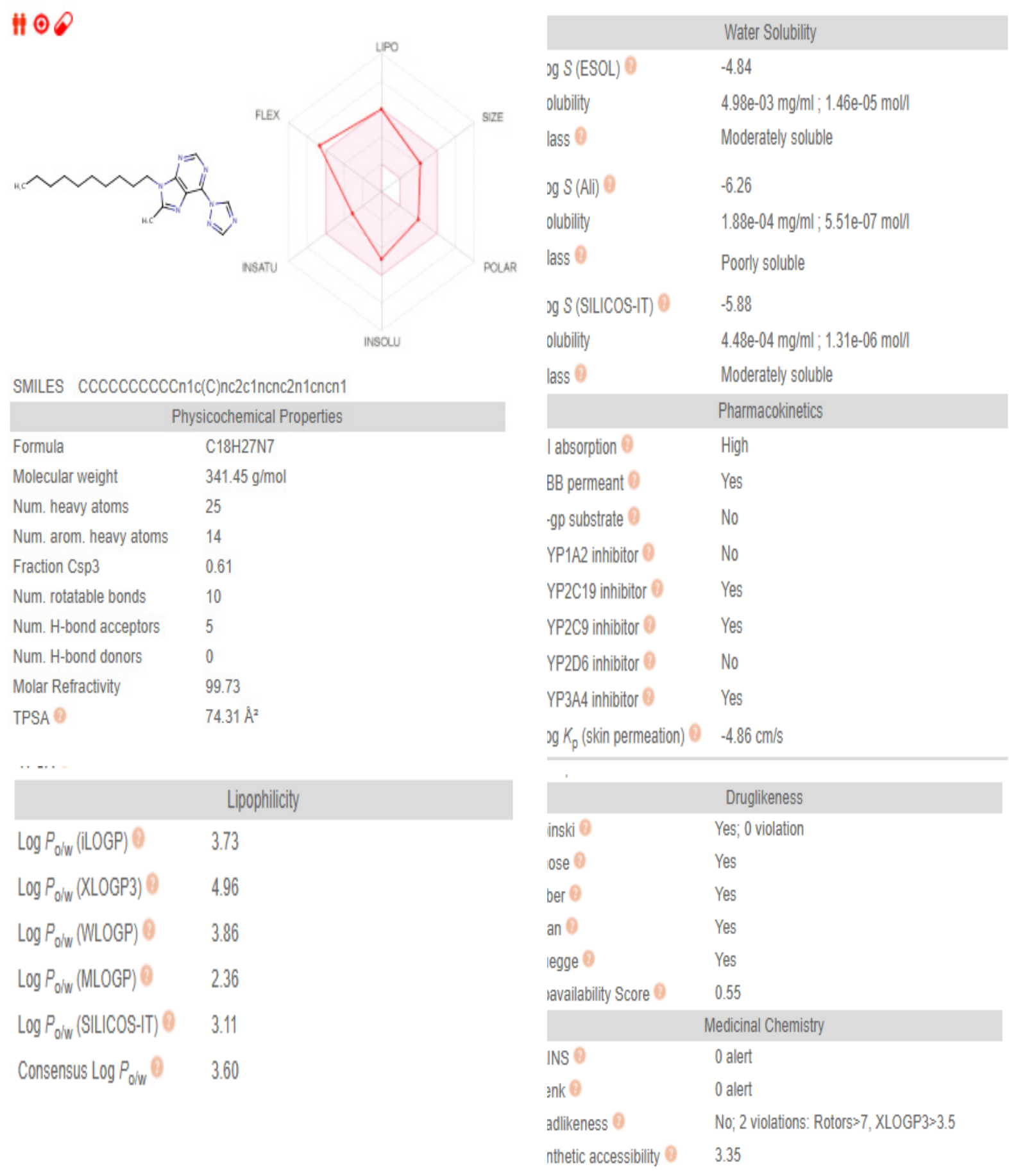

Figure 4. Pharmacokinetic properties of 9-decyl-8-methyl-6-(1H-1, 2, 4-triazol-1-yl)-9H-purine

\section{Conclusion}

In-silico molecular docking study was carefully used to design four AEDs through structural based drug designed technique. The Autoduck vina docking option of Pyrx multipurpose simulation software was used in this study to perform docking simulations. Four anti-epilepsy drug (AED) candidates was designed (Anti-epilepsy disorders) through a structural based drug technique. All the designed AED candidates shows stable binding interaction energies. Out of the four designed compounds, 9-decyl-8-methyl-6-(1H-1, 2, 4-triazol-1-yl)-9H-purine shows better binding energy with $\mathrm{GABA}_{\mathrm{T}}$. The docked energy score of the compound $(7.8 \mathrm{Kcal} / \mathrm{mole})$ was better than the binding energy scores of the standard anti-epilepsy compounds, Carbamazepine $(-6.5 \mathrm{kcal} / \mathrm{mole})$ and Valproate $(-4.5 \mathrm{kcal} / \mathrm{mole})$. Also, the pharmacokinetic properties 
investigation revealed that the best designed AED could be easy to synthesized, absorbed, distributed, metabolized and excreted. Therefore, this drug candidate could be synthesized and used effectively for the treatment and management of epilepsy disorder.

\section{References}

Abdulfatai, U., Uzairu, A., \& Uba, S. (2016). Quantitative structure-activity relationship study of anticonvulsant activity of $\alpha \_$substituted acetamidon-benzylacetamide derivatives. Theoretical and computational chemistry. Cogent chemistry, 2(1). https://doi.org/10.1080/23312009.2016.1166538

Abdulfatai, U., Uzairu, A., \& Uba, S. (2017). Quantitative structure-activity relationship and molecular docking studies of a series of quinazolinonyl analogues as inhibitors of gamma amino butyric acid aminotransferase. Journal of Advanced Research, 8(1), 33-43. https://doi.org/10.1016/j.jare.2016.10.004

Abdulfatai, U., Uzairu, A., \& Uba, S. (2020). Molecular Docking Analysis of Chloroquine and Hydroxychloroquine and Design of Anti-SARS-CoV2 Protease Inhibitor. Modern Applied Science, 14(10), 1913-1852. https://doi.org/10.5539/mas.v14n10p52

Ertl, P., \& Schuffenhauer, A. (2009). Estimation of synthetic accessibility score of drug-like molecules based on molecular complexity and fragment contributions. Journal of Cheminformatics, 1. https://doi.org/10.1186/1758-2946-1-8

Kitchen, D. B., Decornez, H., Furr, J. R., \& Bajorath, J. (2004). Docking and scoring in virtual screening for drug discovery: methods and applications. Nature reviews Drug discovery, 3, 935-949. https://doi.org/10.1038/nrd1549

Langer, T., \& Hoffmann, R. D. (2001). Virtual screening an effective tool for lead structure discovery. Current pharmaceutical design, 7(7), 509-527. https://doi.org/10.2174/1381612013397861

Lipinski, CA. (2016). Rule of five in 2015 and beyond: target and ligand structural limitations, ligand chemistry structure and drug discovery project decisions. Advanced Drug Delivery Reviews, 101, 34-41. https://doi.org/10.1016/j.addr.2016.04.029

Martin, YC. (2005). A bioavailability score. Journal of Medicinal Chemistry, 48(9), 3164-3170. https://doi.org/10.1021/jm0492002

McCormick, D. A., \& Contreras, D. (2001). On the cellular and network bases of epileptic seizures. Annual Review of Physiology, 63, 815-846. https://doi.org/10.1146/annurev.physiol.63.1.815

McNamara, O. J. (2001). Drugs Effective in the Therapy of the Epilepsies. In Hardman, J. G., Limbird, L. E., \& Gilman, A. G. (Eds.), The Pharmacological Basis of Therapeutics (pp. 521-548). McGraw-Hill: New York.

Meador, K. J. (2003). Newer anticonvulsants: dosing strategies and cognition in treating patients with mood disorders and epilepsy. J. Clin. Psychiatry, 64(Suppl. 8), 30-34.

Stangler, T., Mayr, L. M., \& Willbold, D. (2002). Solution structure of human GABAA receptor-associated protein GABARAP: implications for biological function and its regulation. Journal of Biological Chemistry, 277(16), 13363-13366. https://doi.org/10.1074/jbc.C200050200

Storici, P., Capitani, G., Baise, DD., Moser, M., John, RA., \& Jansonius, JN. et al. (1999). Crystal structure of GABA aminotransferase, a target for antiepileptic drug therapy. Biochemistry, 38(27), 8628-8634. https://doi.org/10.1021/bi990478j

Wang, S. B, Jin, P., Li, F. N., \& Quan Z. N. (2014). Synthesis and anticonvulsant activity of novel purine derivatives. European Journal of Medicinal Chemistry, 84, 574-583. https://doi.org/10.1016/j.ejmech.2014.07.074

$\mathrm{Xu}, \mathrm{X}$. et al. (2012). A novel chemometric method for the prediction of human oral bioavailability. Int. J. Mol. Sci., 13(6), 6964-6982. https://doi.org/10.3390/ijms 13066964

\section{Copyrights}

Copyright for this article is retained by the author(s), with first publication rights granted to the journal.

This is an open-access article distributed under the terms and conditions of the Creative Commons Attribution license (http://creativecommons.org/licenses/by/4.0/). 